\title{
HAS MODERNIZATION GONE TOO FAR? Modernity and happiness in 141 contemporary nations
}

\author{
Ruut Veenhoven ${ }^{1}$ and Maarten Berg, \\ Erasmus University Rotterdam, The Netherlands \\ International Journal of Happiness and Development \\ 2013 Vol. 1 No 2 172-195 DOI: 10.1504/IJHD.2013.055645
}

\begin{abstract}
Modern society comes in for a great deal of criticism, such as about increasing individualization, globalization and technologization, which is seen to reduce the quality of life. This claim was investigated in a comparative study of 141 presentday countries. Eight aspects of modernity were considered: industrialization, size of the service sector, economic freedom, real income per capita, globalization, level of education, political democracy and urbanization. Happiness in different countries was measured as the average response to survey questions on happiness, affect and life-satisfaction.

Analysis shows that people living in most modern countries are substantially happier than people in the less modern countries are. The patterns are generally linear. In a subset of Western nations, greater modernity still goes with greater happiness. Although the advantages of societal modernization may be finite, modernization has not yet undermined human happiness.
\end{abstract}

Keywords: happiness, livability, quality of life, modernization

\section{INTRODUCTION}

Criticism of modern society

Society has changed radically since the dawn of mankind, and today it is changing faster than ever. This raises the question as to whether modern society is still compatible with human nature. Has modernization gone too far? Many think so. Several studies in modern nations show rising discontent with the development of society, e.g. widespread belief that society has become harder, less caring and less safe and things will even get worse in the future (e.g. Hagerty 2003, Inglehart \& Welzel 2005, SCP 2004). Such cultural criticism encompasses a range of different views.

There is a long history of people who reject modern society as such and want to return to 'the good old days' that existed before the industrial revolution and democratic reforms took place. Although this radical rejection of modern society is currently still found among Islamic extremists, there is little real support for the view that the clock of social development should be turned back.

A much more common view is that the process of modernization has gone too far in some respects, and that we therefore need to stop moving forward and

\footnotetext{
${ }^{1}$ E-mail: veenhoven@ese.eur.nl
} 
perhaps even take a step backwards in some areas. For instance, there is a great deal of support for the view that international capitalism needs to be curbed and that national identities need to be protected in the face of increasing globalization. Likewise there are misgivings about trends in education, and many want to see a return to smaller schools with stricter teachers. There are also concerns about the demise of the church, civil-society organizations and the nuclear family, and complaints about rising materialism, antisocial behaviour and crime.

The notion that modernization has gone too far has been expressed by leading sociologists such as Ritzer (1993) in 'The MacDonaldization of society', Putnam (2000), in 'Bowling alone' and Etzioni (1993) in 'The spirit of community: The reinvention of American society'. Criticism is not limited to academic circles, and also has political consequences. In this context, governments in rich counties such as Japan, Saudi Arabia and Singapore are attempting, through legislation, educational policy and campaigns, to maintain traditional structures. In WestEuropean countries a variety of political parties are arguing for greater social cohesion and stronger collective identities.

\section{Counter-criticism}

These cultural critics are opposed by people who emphasize the benefits of social modernization, such as increased affluence, greater legal certainty, democracy and freedom of choice. The optimistic view held in this camp is less prominent in the intellectual discourse, but it does dominate in many areas of policy, such as 'development assistance', which is aimed to help countries that 'lag behind' to modernize more quickly.

This view is also represented within sociology. Some of the discipline's founding fathers, including Auguste Comte and Herbert Spencer, supported the process of modernization that occurred during their lifetimes. Optimistic views on progress are not so widely held among present-day sociologists, although some argue that social progress is being achieved, e.g. Patrick Nolan and Gerhard Lenski (2008), who expressed such views in their influential book on macro sociology.

\section{Research questions}

There is something to be said for both views, since it is obvious that there are benefits and drawbacks to modernization. The question is to what extent the benefits outweigh the drawbacks and whether the balance is the same for different aspects of modernization. Another question concerns the optimal extent of modernization.

These questions can be approached from a number of perspectives. This study answers these questions from a utilitarian perspective and investigates the extent to which a country's level of modernity is associated with greater happiness for a greater number of citizens. This perspective is explained in more detail in Veenhoven (2010d). 


\subsection{Modernity within countries}

Modernity is a key concept in sociology and it is one on which sociologists will never fully agree. In common parlance, the term relates primarily to social changes that occur when agrarian societies are industrialized. However, there is disagreement as to what precisely the core features of modernization are. Some emphasize the development of technology and industrialization (Nolan \& Lensky 2008), others place the stress on the greater division of labour and the associated increase in inter-dependency (Elias 2000), while a third group focuses on urbanization and the rise of the nation state (Poggi 1990). Rather than becoming embroiled in this scholastic battle, we will restrict ourselves to looking at several measurable aspects that have a part to play in the debate on whether modernization has had a beneficial effect in terms of quality of life.

\section{Industrialization}

The industrial revolution is a key factor in the modernization of society and is also an issue in the debate on quality of life in modern society. On the one hand, industrialization is thought to lead to alienation, as shown in the Charlie Chaplin film 'Modern Times'. At the same time, industrialization is lauded for bringing benefits such as material affluence and for liberating people from hard manual labour.

\section{Size of service sector}

In late modern societies, the relative importance of the industrial sector has declined, while the service sector has grown in importance. This development is for the most part seen as promoting quality of life, although concerns exist with regard to 'McJobs' and the extent to which economies without an industrial base are tenable in the long term.

\section{Market economy}

Modernization is often closely associated with capitalist market economies. Major differences of opinion exist with regard to the benefits offered by such economies. Marx (1871) depicted capitalism as a cause of impoverishment. Now that it is clear that things panned out differently, criticism has turned to the 'rat race' and 'compulsive consumerism', which are claimed to be induced by the system (e.g. Lane 2000). On the other hand, the free market is thought to be the driving force behind the progress that has led to major improvements in living conditions, and it is also thought to be an activating force that helps keep people on their toes (e.g. Veenhoven 2007).

\section{Globalization}

The above aspects of modernization within countries are paralleled with increased contacts across borders. The effect this has on quality of life is predominantly thought to be negative, partly because it has an impact on national identity and leads to unwelcome foreigners entering the country (Starr 2005), although a few cosmopolitans speak highly of the freedom that globalization leads to and contact with other cultures. 


\section{Affluence}

This all has brought about an unparalleled level of material affluence. However, once again opinion is not entirely favourable. It is argued that new-found affluence undermines traditional affiliations and promotes superficial consumerism, neither of which promotes quality of life (e.g. Lane 2000). On the other hand, affluence is also thought to have led to massive improvements in quality of life in the form of better housing, better healthcare and holidays in farflung places.

\section{Level of education}

The modernization of society is also associated with rising levels of education.

People living in modern societies currently spend around a quarter of their lives in schools. Although a very small number of people consider this to be undesirable (e.g. Illich 1971), in intellectual circles this is overwhelmingly viewed as something that makes a positive contribution to quality of life.

\section{Democracy}

The modernization of society is also linked with political democracy. Political democracy is often viewed as a source of happiness since the system ensures that the wishes of the citizens are heard. Yet, not everyone considers democracy to be conducive to happiness. Autocratic rulers often depict democracy as a source of division and legitimize their rule with arguments related to quality of life.

\section{Urbanization}

The modernization of society is also accompanied with migration from the country to towns and cities, and this trend is still continuing unabated. Once again, there are different views on how this affects quality of life. While there is an abundance of literature on 'urban malaise', which makes much of the disadvantages of city life, there are also studies that portray the pleasant aspects of cosmopolitan urban living. These views are described by Wirth (1938) and Fischer (1984), among others.

\subsection{Happiness within countries}

In this discussion, it is important to distinguish between the quality of a society and the quality of life within a society (Veenhoven 2009a). The quality of a society relates to the quality of various aspects of the social system, such as its stability and the contribution it makes to human civilization. The quality of life within a society, however, relates to the extent to which people flourish under that system. This article focuses on quality of life within societies, which is also referred to as 'livability' of society.

When measuring quality of life in different countries it is also important to distinguish between assumed quality and apparent quality of life (Veenhoven 2005). In the former case, quality of life is existence of conditions that are considered as favourable, such as a high level of income, good health care and education. However, using this approach would lead to circular reasoning in this discussion. Quality of life in different countries would then be assessed on the 
basis of the existence of features that are typical of modern countries, such as affluence, healthcare and education. We therefore have not made any use of measures such as the Human Development Index (UNDP 1990) or the Index of Social Progress (Estes 1984). We measured quality of life as experienced personally by people, using responses to survey questions on subjective enjoyment of life, which reflects the 'apparent' quality of living conditions in their countries.

Concept of happiness

'Happiness' is taken to be 'life-satisfaction', i.e. the subjective appreciation of one's life as a whole. This concept is described in further detail by Veenhoven (1984, chapter 2).

\section{Components of happiness}

When assessing how much we like the life we live, we use two sources of information: how well we feel most of the time and how well we do with respect to standards of the good life. These sub-appraisals are referred to as the affective and cognitive 'component' of happiness, and Veenhoven (2009b) assumes that they are determined by different factors; the affective component is primarily determined by the gratification of universal human needs and the cognitive component by the meeting of culturally variable wants.

The extent to which these components of happiness are related to the level of modernity in a country may therefore vary. If modern society is not well compatible with human nature but does fit common standards of the good life, people may feel miserable yet still be contented. Conversely, it is also possible that people living in traditional societies may feel great but nevertheless be discontented because they judge their own situation by the standards of modern countries.

\section{Links to utilitarian philosophy}

The evaluation of social developments in terms of their impact on happiness is linked to the 'utilitarian' philosophy of Jeremy Bentham (1789). According to this consequentionalist view, the moral worth of every action is determined by the extent to which it contributes to "the greatest happiness for the greatest number of people". The same also holds in the case of actions that affect the organization of society. This view is referred to as 'political utilitarianism' or 'rule utilitarianism'.

Bentham took happiness to be "the sum of pleasures and pains", and this definition is highly compatible with the empirical research on 'life-satisfaction' that we have used in this study. The moral principle relates to the happiness of "the greatest number" and as such requires that modernization is assessed in terms of its consequences for the happiness of all of humanity. In this study we come close to that, since our data cover about $95 \%$ of the world's population.

\subsection{Previous research into modernity and happiness}

The relationship between modernity and happiness has been studied before. One line of research is at the micro level of individuals and focuses on whether 
modern-oriented people are happier than traditionalists (e.g. Inkeles 1970). Another strand of research relates to the macro level of countries. Two methods are used in this line of research: comparisons of different countries at a single point in time, and comparisons of the same countries over the course of time. In such studies, no distinction has been made between 'overall' life satisfaction and the 'components' of happiness referred to above.

\section{Comparisons across countries}

The first analysis of modernity and happiness in different countries was performed by Cantril (1965) and covered 14 countries around 1960. In this analysis, modernity was measured using an index that incorporated various aspects of modernization, such as income per capita, the number of doctors, the number of cars, radio, energy consumption, urbanization and education. A strong association with life-satisfaction was discovered $(r=+0.67)$. In the 1990s, research into the relationship between happiness and support for modern values was conducted as part of the World Values Survey. This also revealed a clear positive association (Inglehart \& Welzel 2005). Research has also been conducted into the extent to which happiness is associated with a range of other aspects of modernity, including industrialization, urbanization, democracy and equal rights for women.

The results of all this research have been brought together in the World Database of Happiness (Veenhoven 2010a), specifically in the 'Correlational Findings' collection, section N4 ('Findings on Happiness and Conditions in one's Nation'). In almost all cases, modernity is associated with greater happiness. This association is not equally strong for all aspects of modernity. For example, happiness has been found to be more strongly correlated to affluence than to level of education.

Although the number of countries covered by studies continues to grow, most studies cover fewer than 50 countries. Modern countries tend to be strongly overrepresented, as a result of which studies say more about differences between more modern and less modern countries than they do about differences between modern societies and traditional societies.

The significance of the number of countries covered in a study is indicated by, among other things, the history of the study of the relationship between affluence and happiness. One of the first studies covering a limited number of countries did not find any link between affluence and happiness (Easterlin 1973) and supported the notion that money does not buy happiness. Subsequent research covering a larger number of countries revealed a curvilinear relationship, supporting the theory that affluence is subject to the law of diminishing returns (Veenhoven 1989). More recent research covering over 100 countries shows a linear association: even the logarithm function was found to show a straight line (Deaton 2008).

\section{Comparisons within countries over time}

If the modernization of a society promotes quality of life, this ought to be reflected in increasing average levels of happiness in modernizing countries. In this 
context, it is interesting to look at time trends of happiness in different countries, which are also available in the World Database of Happiness (collection 'Happiness in Nations'). Time trends going back 30 years or even longer are available for 12 modern countries (Veenhoven 2010b). Analysis of these time trends produces a mixed picture.

It is apparent that average levels of happiness in most Western countries have risen, and in Italy they have risen by a whole point on a scale of 0-10. The average has also risen by half a point in Denmark, which is remarkable since Denmark is currently the happiest country in the world and it had therefore seemed logical that happiness would reach a ceiling in that country (Veenhoven \& Hagerty 2005).

This pattern of increasing happiness is not observed everywhere. Average levels of happiness have remained stable in the Britain and declined in Belgium. It is not clear whether average happiness has risen in the USA. The level has gone up slightly since the 1970s, but when compared with the first surveys conducted in the late 1940s it seems as though no progress has been made. This may be related to the post-war euphoria or to small differences in the way the questions used in the surveys were formulated. Anyway, if happiness has increased at all in the USA, it has not increased by much.

In Japan, happiness has remained more or less unchanged since it was first measured in 1958, and the same is true of South Korea since 1980. In China, average levels of happiness have in fact fallen since they were first measured in 1990. This is striking as these countries have undergone rapid modernization during these periods. A possible explanation is that rapid social change initially leads to many adjustment issues (Hays 1984) and rises in happiness are therefore only observed in the long term. A similar phenomenon was observed in former Eastern Bloc countries, where, following the revolutions, happiness fell in 1990 and did not start to rise until around the year 2000 (Baltatescu 2006).

The available trend data do not provide a definitive answer to the question as to whether modernization ultimately leads to greater happiness. We will need to wait at least another 25 years, until time series have increased sufficiently and a new generation has taken over. Until that time, we will have to make do with cross-sectional comparisons of countries.

\subsection{Contribution made by this study}

This article revisits the relationship between modernity and happiness by comparing across present-day countries. It contributes to this line of research in the following ways.

- More countries are compared than ever before. The aforementioned studies covered between 14 and 80 countries. This study covers no fewer than 141 countries and covers $95 \%$ of the world's population.

- As well as calculating linear associations, this study also looks at non-linear patterns in order to identify any upper limits and turning points that may exist.

- In order to spot signs that modernization may be 'going too far', 22 Western countries have been analysed separately. 
- A distinction has also been made between 'overall' happiness (lifesatisfaction) and the 'affective' and 'cognitive' components of happiness.

\section{METHOD}

\subsection{Measuring modernity within countries}

This study did not make any use of multi-dimensional indexes of modernity. Instead, the aspects of modernity discussed in section 1.1 were measured separately.

The extent of industrialization within a country was measured on the basis of the percentage of the economy accounted for by the industrial sector. Data were obtained from the World Fact Book (CIA 2009). Data are available for 176 countries, which is more than the number of countries for which happiness data are available (148) ${ }^{1}$.

The share of the economy accounted for by the service sector was also measured as a percentage of gross domestic product (GDP), again using data derived from the CIA's World Fact Book. Data on the size of the service sector are available for 176 countries $^{2}$.

The functioning of a capitalist market economy in a country was measured using the Heritage Foundation's Index of Economic Freedom (2007). Economic freedom is taken to include the free movement of goods and capital, a low level of government intervention in the economy, and the protection of property rights. Data on economic freedom are available for 155 countries $^{3}$.

The extent of a country's globalization was measured using a Globalization Index based on various indicators covering the economic, social and political dimensions of globalization (Dreher 2010). This index provides data on 181 countries $^{4}$.

Material affluence was measured using purchasing power parity (PPP) per capita. This is a variation of the usual measure of GDP per capita that takes account of differences in the cost of living in different countries. The data on PPP per capita were obtained from the Human Development Report (UNPD 2007). Data exist for 166 countries ${ }^{5}$.

The level of education in a country was measured using the UNDP's Education Index (2007). This index reflects the adult literacy rate and the proportion of the population enrolled in education, with two-thirds weight given to adult literacy and one-third weight given to enrolment. This index provides data on 168 countries $^{6}$.

Democracy was measured using an index that combines the following indicators: electoral process and pluralism, the functioning of government, political participation, political culture and civil liberties. This index is expressed as scores between 0 and 10. Data were obtained from The Economist and are available for 137 countries. $^{7}$

In this study, the extent of urbanization in a country was measured on the basis of the percentage of people living in an urban environment. Data were 
obtained from the Human Development Report (UNPD 2007) and are available for 168 countries $^{8}$.

\subsection{Measuring happiness in different countries}

In section 1.2 'happiness' was described as the subjective appreciation of one's life as a whole. As such, happiness is something that people have in mind and can therefore be measured by asking people about it. As happiness is an overall assessment, a single question is all that is necessary. It is partly for this reason that it is frequently included in large-scale public surveys. There were initially many misgivings about this method, including doubts as to whether honest responses would be given and whether comparisons could be made between countries. However, on further investigation these misgivings turned out to be unfounded (Veenhoven 2002).

Life-satisfaction

In this study, 'overall happiness' was measured using the following question:

All things considered, how satisfied are you with your life as a whole these days?

$\begin{array}{lllllllllll}0 & 1 & 2 & 3 & 4 & 5 & 6 & 7 & 8 & 9 & 10\end{array}$

dissatisfied satisfied

Responses to this question are available for 148 countries. Data were obtained from various studies conducted as part of the World Values Survey and the Gallup World Poll ${ }^{9}$.

\section{Affect balance}

The affective component of happiness was measured using 14 questions about emotions, such as anger, love and pride, which were asked in the Gallup World Poll. The question is always whether the respondent experienced the relevant emotion at some time during the previous day. We calculated the average number of affirmative answers to questions about positive emotions and to questions about negative emotions for each country. The 'affect balance' was then calculated by subtracting the average number of negative emotions from the average number of positive emotions in each county. These data are available for 138 countries and cover the period 2006-2009 ${ }^{10}$.

\section{Contentment}

The cognitive component of happiness was measured using a question about how close the respondent's life was to the best he could think of. This question was worded in the following way:

Imagine a ladder with eleven rungs, which are numbered from 0 at the bottom to 10 at the top. Suppose that the top of the ladder represents the best possible life for you and the bottom of the ladder the worst possible life. Where on this ladder do you feel that you stand at the present time? 
Responses to this question are available for 139 countries, and were obtained as part of the Gallup World Poll ${ }^{11}$.

\subsection{Analysis}

The aforementioned aspects of modernity in each country were compared separately against the average level of happiness in those countries. We started with a bi-variate analysis, which consisted of the following steps.

\section{Visual inspection of scatter plots}

The relationship between various indicators of modernity and happiness was investigated using a number of scatter plots (not all of these are presented in this article due to a lack of space). Scatter plots show in a glance whether there is a statistical association and whether there is a levelling off or a turning point at the top. Since each country is identifiable in the scatter plots, we can interpret general trends within the context of the knowledge that we have of the countries in question.

\section{Calculation of correlations}

In addition, the strength and direction of the associations are also expressed in correlation coefficients. We made a distinction between negligible correlations ( 0 $-0.20)$, weak correlations $(0.20-0.30)$, strong correlations $(0.30-0.50)$ and very strong correlations $(>0.50)$.

No tests of significance

In contrast to common practice, we have not examined whether the observed correlations are statistically significant. Tests of significance indicate the probability of a Type I error, i.e. the chance of a statistical difference being found in a sample when this difference does not exist in the population. If this probability is sufficiently low (i.e. no more than $5 \%$ ), it can be concluded that the association cannot be attributed to the composition of the sample and actually exists within the population. In other words, a low p-value indicates it is unlikely that the association would disappear if another sample was taken. However, this study did not use random sampling. All of the countries for which the necessary data were available were included in the analyses. Since there is no possibility of a Type I error occurring, any judgments about statistical significance are meaningless. Therefore we suffice with the effect size.

\section{Linearity testing}

The correlation coefficients reported here only indicate the extent of any linear association. It may, however, be the case that while there is a positive association between modernity and happiness, this association also has a turning point. For this reason we also looked at the quadratic fit. With regard to the quadratic fit, a further distinction was made between upward curving parabolic fits (smiles) and downward curving parabolic fits (frowns). The shape that best fits the data for each indicator was determined. Since data points never form a straight line, there is a risk that this 'data-driven' method will reveal all 
kinds of random variations. Simply looking to see whether a linear fit or a quadratic fit has the greatest explained variance is therefore not enough. As quadratic fits offer an extra degree of freedom, the explained variance will always be greater in the case of a quadratic fit. This therefore means that the difference between the explained variance in a quadratic fit and the explained variance in the corresponding linear fit must be large enough to compensate for the difference in degrees of freedom. To this end, we compared the simple (linear) model with the expanded (quadratic) model using a -2 log likelihood test.

\section{Controlling for other aspects of modernity}

As the aspects of modernity covered in this study form part of a more comprehensive syndrome of modernity, it is difficult to determine the separate contribution made by each aspect of modernity to happiness. Spurious associations can easily be made, for example if a positive correlation between level of education and happiness in nations is in fact due entirely to affluence. It is even possible that negative effects may disappear from view, for example if the negative effect of a free market economy is hidden by the positive effects of democracy.

It is not easy to solve this problem in a study with a cross-sectional design, and the application of a multiple regression model with many variables, such as used by Bjornskov et al (2008), is problematic to say the least (see also Berg \& Veenhoven (2010) for a more detailed discussion of these problems). We have therefore restricted ourselves to calculating partial correlations in which only the level of affluence in a country was controlled for. We decided to control for affluence as this is the variable that best covers the syndrome of modernity. As mentioned above, affluence was measured using PPP per capita.

If a statistical association disappears when it is controlled for affluence, this does not necessarily mean that there is no reality link with happiness. For example, if controlling for affluence reduces the association between happiness and level of education, this reduction might be due to the fact that education leads to higher levels of affluence and promotes happiness as a consequence.

Separate analysis of 22 Western countries

Criticism of modernization is aimed not so much at all forms of progress but at alleged excesses. Any positive association between modernity and happiness at a global level does not rule out the possibility that there may be a negative association between happiness and modernity in Western countries. We therefore also analysed Western countries separately. The Western countries covered in this study were Australia, Austria, Belgium, Canada, Denmark, Finland, France, Germany, Greece, Iceland, Ireland, Italy, Luxembourg, the Netherlands, New Zealand, Norway, Portugal, Spain, Sweden, Switzerland, the United Kingdom and the United States. Separate study of this relatively homogeneous subset of Western countries will also reduces the influence of many extraneous variables that might confuse the relationship between modernity and happiness. 
In sum: we studied each indicator of modernity in relation to three indicators of happiness in six different ways:

1. The extent of any linear association between modernity and happiness at a global level;

2. The kind of association (linear or quadratic) that exists between modernity and happiness at a global level;

3. The extent of any linear association between modernity and happiness at a global level after adjustment for PPP;

4. The extent of any linear association between modernity and happiness in the Western world;

5. The kind of association (linear or quadratic) that exists between modernity and happiness in the Western world;

6. The extent of any linear association between modernity and happiness in the Western world after adjustment for PPP.

\section{$3 \quad$ RESULTS}

Table 1 shows that at a global level all indicators of modernity are positively associated with average levels of happiness within countries, even after controlling for affluence in those countries.

\subsection{Industrialization and happiness}

The relationship between industrialization and overall happiness is quite weak ( $r=$ +0.15 ), which denotes an explained variance of $2.4 \%$. However, the quadratic fit is significantly better (6.5\%). The linear association between industrialization and happiness also exists after controlling for affluence $\left(r_{p}=+0.15\right)$, which suggests that this is not a spurious association.

\section{Table 1}

Correlations between modernity and overall happiness in 141 countries

\begin{tabular}{|l|c|c|c|}
\hline Variable & $\begin{array}{c}\text { Correlation with } \\
\text { happiness }\end{array}$ & $\begin{array}{c}\text { Explained variance - } \\
\text { linear and quadratic } \\
\text { associations }\end{array}$ & $\begin{array}{c}\text { Control for } \\
\text { affluence }\end{array}$ \\
\hline Industrialization & +0.15 & $\begin{array}{c}\text { Linear: } 0.024 \\
(\mathrm{~N}=141)\end{array}$ & +0.15 \\
Quadratic: $\mathbf{0 . 0 6 5} \mathbf{d}$ & Linear: 0.234 \\
Quadratic: $0.237 \mathrm{u}$ & +0.16 \\
\hline $\begin{array}{l}+0.48 \\
\text { sector }\end{array}$ & $\begin{array}{c}\mathrm{N}=141) \\
(\mathrm{N}=136)\end{array}$ & $\begin{array}{c}\text { Linear: } 0.383 \\
\text { Quadratic: } 0.386 \mathrm{~d}\end{array}$ & +0.22 \\
\hline $\begin{array}{l}\text { Free market } \\
\text { economy }\end{array}$ & +0.70 & $\begin{array}{c}\text { Linear: } 0.487 \\
\text { Quadratic: } 0.489 \mathrm{~d}\end{array}$ & +0.34 \\
\hline Globalization & $+\mathrm{N}=136)$ & Linear: 0.406 & - \\
$(\mathrm{N}=137)$ & Quadratic: $0.449 \mathrm{u}$ & Linear: 0.417 & +0.65 \\
\hline Affluence & +0.65 & &
\end{tabular}




\begin{tabular}{|l|c|c|c|}
\hline & $(\mathrm{N}=139)$ & Quadratic: $\mathbf{0 . 4 3 5} \mathbf{u}$ & \\
\hline Democracy & +0.61 & Linear: 0.372 & +0.27 \\
& $(\mathrm{~N}=133)$ & Quadratic: $\mathbf{0 . 4 4 6} \mathbf{u}$ & \\
\hline Urbanization & +0.62 & Linear: 0.387 & +0.33 \\
& $(\mathrm{~N}=138)$ & Quadratic: $0.388 \mathrm{u}$ & \\
\hline
\end{tabular}

A ' $d$ ' in the central column indicates a downward curving parabola, while a ' $u$ ' indicates an upward curving parabola. Instances where the quadratic fit is significantly better than the linear fit are shown in bold.

So in this world sample we see a positive correlation. How about the Western nations in particular? The correlation in Table 2. is even stronger $(r=+0.26)$ and even more so after controlling for affluence $\left(r_{p}=+0.34\right)$, which contradicts the notion that industrialization has gone too far.

\section{Table 2}

Correlations between modernity and overall happiness in 22 Western countries

\begin{tabular}{|c|c|c|c|}
\hline Variable & $\begin{array}{c}\text { Correlation with } \\
\text { happiness }\end{array}$ & $\begin{array}{l}\text { Explained variance - } \\
\text { linear and quadratic } \\
\text { associations }\end{array}$ & $\begin{array}{l}\text { Control for } \\
\text { affluence }\end{array}$ \\
\hline Industrialization & $\begin{array}{c}+0.26 \\
(\mathrm{~N}=21)\end{array}$ & $\begin{array}{c}\text { Linear: } 0.065 \\
\text { Quadratic: } 0.072 \mathrm{u}\end{array}$ & +0.34 \\
\hline $\begin{array}{l}\text { Size of service } \\
\text { sector }\end{array}$ & $\begin{array}{c}-0.23 \\
(\mathrm{~N}=21)\end{array}$ & $\begin{array}{c}\text { Linear: } 0.054 \\
\text { Quadratic: } 0.068 \mathrm{u}\end{array}$ & -0.35 \\
\hline $\begin{array}{l}\text { Free market } \\
\text { economy }\end{array}$ & $\begin{array}{l}+0.66 \\
(\mathrm{~N}=22)\end{array}$ & $\begin{array}{c}\text { Linear: } 0.429 \\
\text { Quadratic: } 0.468 \mathrm{~d}\end{array}$ & +0.55 \\
\hline Globalization & $\begin{array}{l}+0.15 \\
(\mathrm{~N}=22)\end{array}$ & $\begin{array}{c}\text { Linear: } 0.022 \\
\text { Quadratic: } 0.116 \mathrm{u}\end{array}$ & +0.15 \\
\hline Affluence & $\begin{array}{l}+0.53 \\
(\mathrm{~N}=22)\end{array}$ & $\begin{array}{c}\text { Linear: } 0.281 \\
\text { Quadratic: } 0.590 \mathrm{~d}\end{array}$ & - \\
\hline Education & $\begin{array}{c}+0.25 \\
(\mathrm{~N}=22)\end{array}$ & $\begin{array}{c}\text { Linear: } 0.063 \\
\text { Quadratic: } 0.179 \mathrm{u}\end{array}$ & +0.56 \\
\hline Democracy & $\begin{array}{l}+0.75 \\
(\mathrm{~N}=22)\end{array}$ & $\begin{array}{c}\text { Linear: } 0.556 \\
\text { Quadratic: } 0.582 \mathrm{~d}\end{array}$ & +0.71 \\
\hline Urbanization & $\begin{array}{c}+0.46 \\
(\mathrm{~N}=22)\end{array}$ & $\begin{array}{c}\text { Linear: } 0.212 \\
\text { Quadratic: } 0.254 \mathrm{~d}\end{array}$ & +0.38 \\
\hline
\end{tabular}

A ' $d$ ' in the central column indicates a downward curving parabola, while a ' $u$ ' indicates an upward curving parabola. Instances where the quadratic fit is significantly better than the linear fit are shown in bold.

\subsection{Size of service sector and happiness}

There is a strong linear association between the size of the service sector and average happiness in countries $(r=+.48)$. This positive association becomes considerably weaker when affluence is controlled $\left(r_{p}=+0.16\right)$. Clearly the service sector is larger in more prosperous countries. 
If we look exclusively at Western countries, we see a weak negative association $(r=-0.23)$. After controlling for affluence, this negative association becomes stronger $\left(r_{p}=-0.35\right)$. This makes the size of the service sector the only indicator of happiness that has a negative association with happiness (and even this is found only in the subset of Western countries). All other indicators show positive associations with happiness.

\subsection{Free market economy and happiness}

A free market economy is very strongly associated with happiness $(r=+0.62)$. This association is shown in the scatter plot in Figure $1^{12}$. The association can be explained to a large extent by the higher levels of affluence in countries with free market economies, although a weak positive association still remains after controlling for affluence $\left(r_{p}=+0.22\right)$.

\section{Figure 1}

Relationship between free market economy and happiness in 136 countries

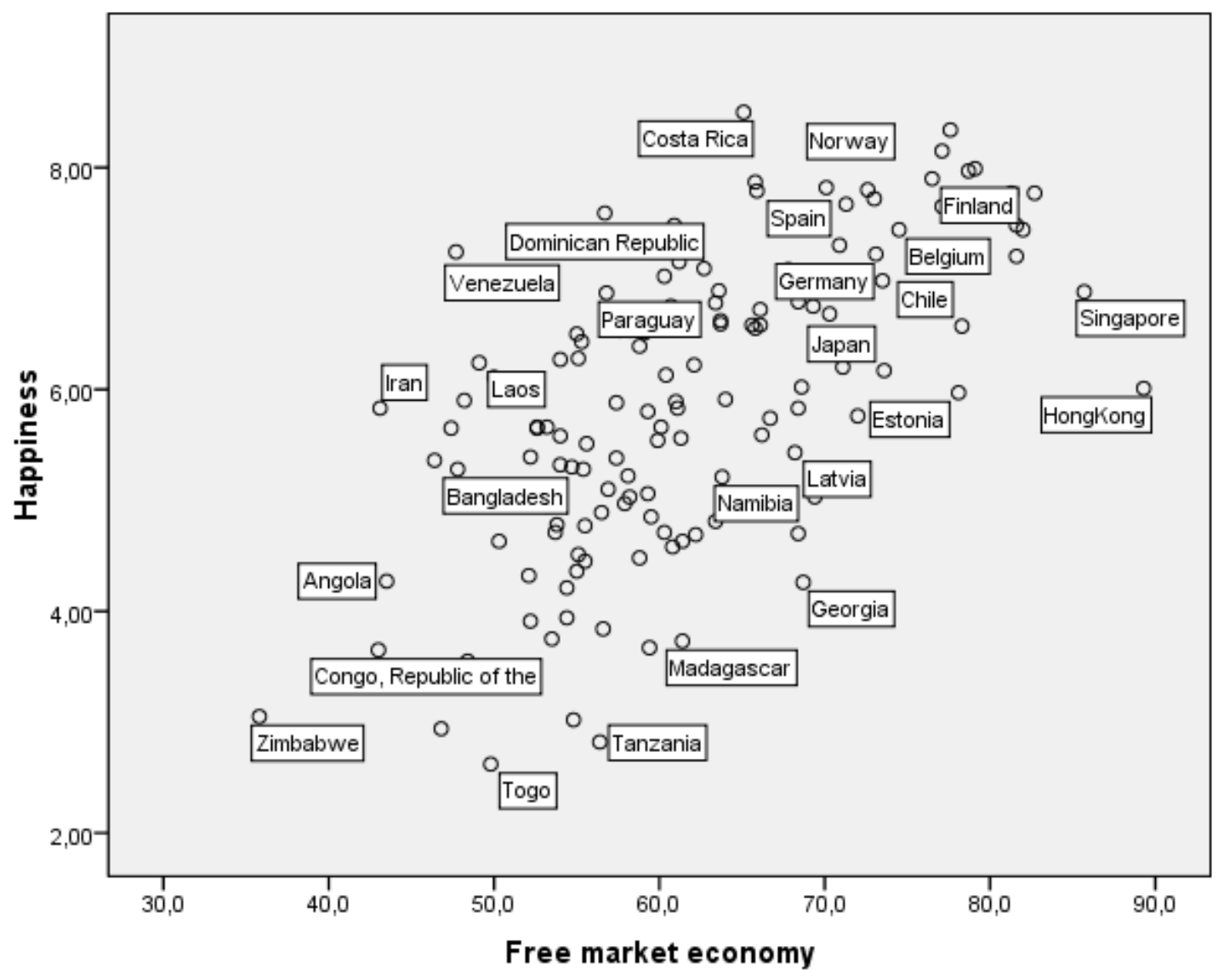


The results are even clearer when looked at in the Western context. The zeroorder correlation is no less than +0.66 , and even after controlling for affluence the positive association remains very strong $\left(r_{p}=+0.55\right)$.

\subsection{Globalization and happiness}

The extent of globalization also has a very strong positive association with happiness at a global level $(r=+0.70)$. There is still a strong positive association after controlling for affluence $\left(r_{p}=+0.34\right)$.

The associations are weaker when considered in a Western context, but they are still positive. The zero-order correlation is +0.15 , and the partial correlation after controlling for affluence is also +0.15 .

\subsection{Affluence and happiness}

There is a very strong linear association between affluence and happiness ( $r=$ +0.64 ). However, both Table 1 and Figure 2 show that a quadratic fit is better in this case. That said, on visual inspection it is not possible to identify an actual turning point. In other words, there seem to be no countries on the right-hand side of the downward curving parabola. For this reason, Figure 2 exhibits more of the features of a logarithmic pattern. 


\section{Figure 2}

Relationship between affluence and happiness in 137 countries

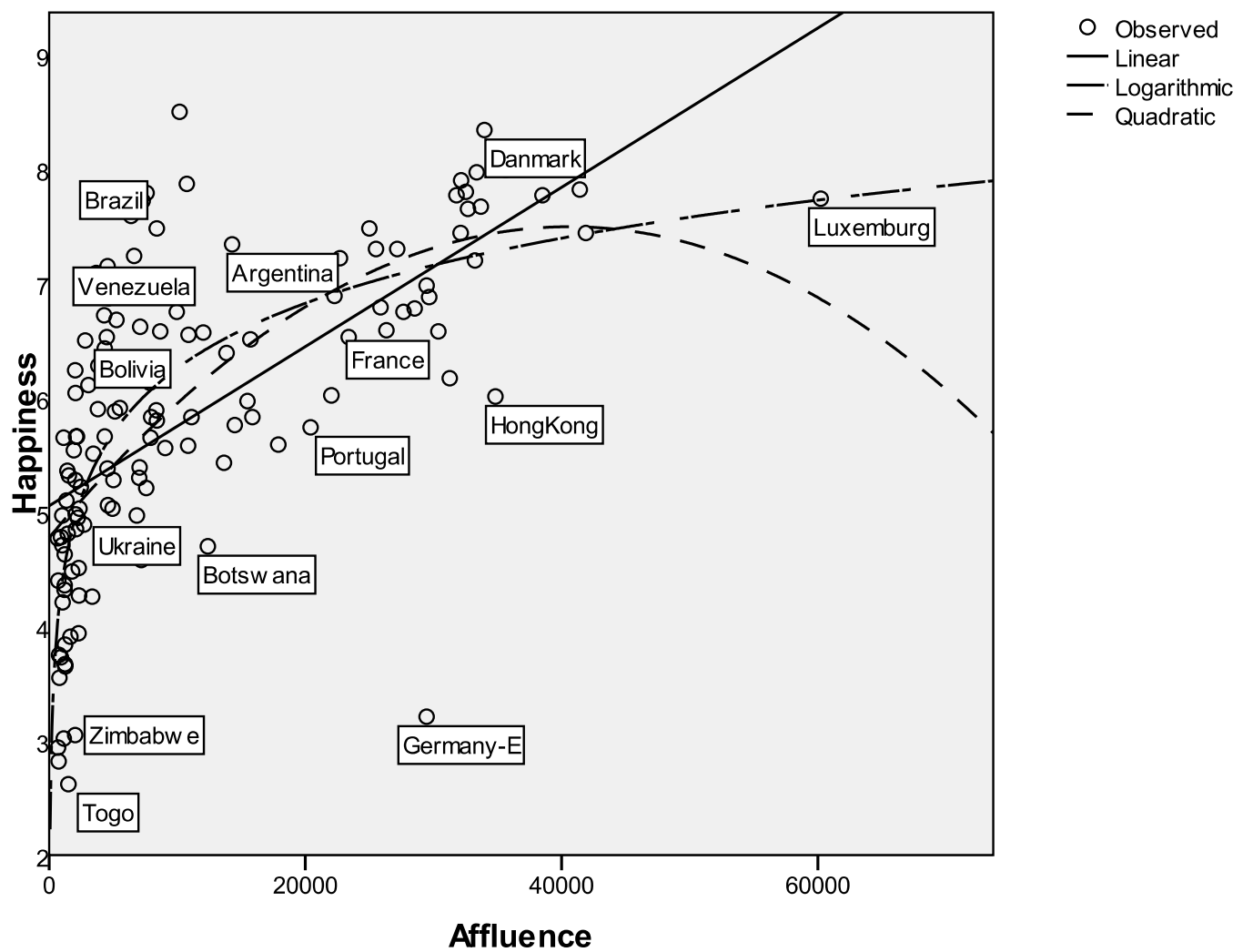

Given the pattern of diminishing returns at a global level, one might expect a much weaker association between affluence and happiness in the context of Western countries. However, these countries also show a very strong positive association $(r=+0.53)$. That said, Table 2 ? shows that a downward curving parabolic fit is a significantly better fit. Whereas the linear association between affluence and happiness explains $28.1 \%$ of the variances in happiness within this subset of Western countries, no less than $59.0 \%$ of the explained variance is covered by a downward curving parabolic fit.

\subsection{Education and happiness}

Education also has a very strong positive association with happiness $(r=+0.65)$. When affluence is kept constant, this positive association remains intact $\left(r_{p}=\right.$ +0.65 ). That said, an upward curving parabolic fit is better than a linear fit, as it results in an explained variance of $43.5 \%$, compared with $41.7 \%$.

Within Western countries, the correlation between education and happiness is weaker $(r=+0.25)$. It is striking that in Western countries control for affluence results in a stronger correlation $\left(r_{p}=+0.56\right)$ than the zero-order correlation. This is shown in the scatter plot in Figure 3. The level of education in Western countries was compared against these countries' residual happiness scores. These residual scores show the extent to which countries are happier or 
unhappier than could be expected based on their levels of affluence. Levels of happiness in countries with positive residual scores (such as Denmark) are higher than the levels that can be explained by their levels of affluence. By contrast, countries with negative residual scores (such as Portugal) are relatively unhappy.

\section{Figure 3}

Relationship between education and happiness after control for affluence in 22 Western countries

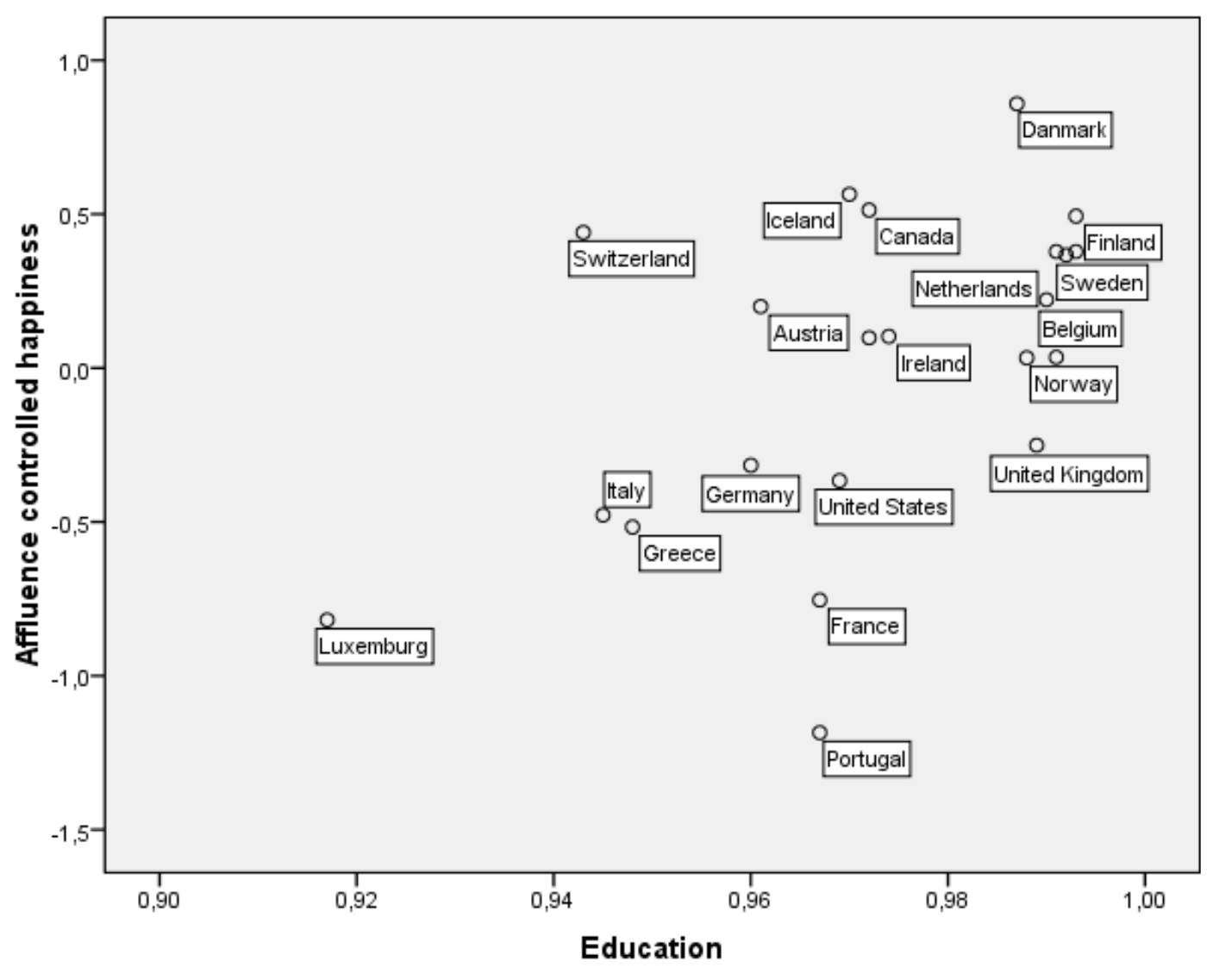

\subsection{Democracy and happiness}

The level of democracy also turns out to be very strongly associated with happiness $(r=+0.61)$. In addition, the upward curving parabolic fit is even better. The linear relationship between democracy and happiness explains $37.2 \%$ of the variance between countries, while the upward curving parabolic relationship explains $44.6 \%$ of this variance. An independent association still exists after control for affluence, although this is weaker $\left(r_{p}=+0.34\right)$.

Given the upward curving parabolic association at a global level, it might be expected that there is also a strong positive association between democracy and happiness in Western countries. This is indeed the case. The correlation is no less than +0.75 , while the partial correlation after control for affluence is +0.71 . 


\subsection{Urbanization and happiness}

The extent of urbanization is no exception to the rule that aspects of modernization are positively associated with happiness. The correlation at a global level is +0.62 . After control for affluence, this is +0.33 .

There is also a strong positive correlation in Western countries $(r=+0.46)$. Much of this positive correlation remains after control for affluence $\left(r_{p}=+0.38\right)$.

\subsection{Associations with components of happiness}

Due to a lack of space we will not report here all the results of the associations with the two components of happiness ${ }^{13}$ : affect balance and contentment. Instead, we point out some important findings below.

\section{Contentment}

The correlations between aspects of modernity and the cognitive component of happiness (contentment) were almost identical to the above mentioned correlations with overall happiness. At a global level, all correlations are positive without exception. Within the 22 Western countries almost all correlations are positive, with just two exceptions. The first exception relates to the extent of industrialization. Although this is positively associated with contentment ( $r=$ +0.21 ), after controlling for affluence there is a negligible negative association $\left(r_{p}=-0.10\right)$. The other exception relates to the size of the service sector. In this case, the zero-order correlation with contentment is -0.18 .

\section{Affect balance}

The correlation between modernity of nations and the affective component of happiness (affect balance) were not so similar to the results for overall happiness. First, the correlations are generally less strong, at least at a global level. Second, although positive correlations still dominate, a number of weak negative correlations can also be seen. At a global level, we discovered a negligible negative association between industrialization and affect $(r=-0.01)$. When we controlled for affluence, we discovered weak negative correlations with industrialization $\left(r_{p}=-0.09\right)$, globalization $\left(r_{p}=-0.02\right)$, education $\left(r_{p}=-0.05\right)$ and urbanization $\left(r_{p}=-0.06\right)$.

When we studied the relationship between modernity and affect balance in Western countries, we found a strong negative correlation between the size of the service sector and affect $(r=-0.33)$. However, this negative association was reduced when we controlled for affluence $\left(r_{p}=-0.13\right)$.

\section{DISCUSSION}

The question raised in this article is whether modernization has gone too far. In this discussion we will first summarize the results of the current study, after which we will discuss a number of explanations. 


\subsection{Summary of results}

\section{Global pattern}

The relationship between modernity and happiness was investigated in a total of 90 different ways in this study. Eight indicators of modernity were used: the extent of industrialization, the size of the service sector, economic freedom, globalization, affluence, education, democracy and urbanization. The association with happiness was calculated for each of the eight indicators (zero-order correlation). The association with happiness after adjusting for affluence (partial correlation) was calculated for all indicators except affluence itself. Separate calculations of all 15 associations were made for the world as a whole and the subset of Western countries. The dependent variables were happiness and the two components of happiness: affect balance and satisfaction. The frequency distribution of positive and negative correlations is shown in Table 3.

Table 3

Number of positive and negative associations between modernity and happiness

\begin{tabular}{|l|c|c|c|}
\hline Strength of association & $\begin{array}{c}\text { Number of } \\
\text { positive } \\
\text { associations }\end{array}$ & $\begin{array}{c}\text { Number of } \\
\text { negative } \\
\text { associations }\end{array}$ & Total \\
\hline All associations & 16 & 8 & 24 \\
\hline Negligible $(0-0.20)$ & 12 & 1 & 13 \\
\hline Weak $(0.20-0.30)$ & 20 & 2 & 22 \\
\hline Strong $(0.30-0.50)$ & 31 & 0 & 31 \\
\hline Very strong $(>0.50)$ & 79 & 11 & 90 \\
\hline Total & & & \\
\hline & & & \\
\hline Associations at global & & 5 & 16 \\
\hline level & 11 & 0 & 7 \\
\hline Negligible $(0-0.20)$ & 7 & 0 & 8 \\
\hline Weak $(0.20-0.30)$ & 8 & 0 & 14 \\
\hline Strong $(0.30-0.50)$ & 40 & 5 & 45 \\
\hline Very strong $(>0.50)$ & & & \\
\hline Total & & & \\
\hline & 5 & 3 & 8 \\
\hline Associations for Western & 5 & 1 & 6 \\
\hline countries & 12 & 2 & 14 \\
\hline Negligible $(0-0.20)$ & 17 & 0 & 17 \\
\hline Weak $(0.20-0.30)$ & 39 & 6 & 45 \\
\hline Strong $(0.30-0.50)$ & & & \\
\hline Very strong $(>0.50)$ & & & \\
\hline Total & & & \\
\hline
\end{tabular}

Of the 90 associations between happiness (or components of happiness) and aspects of modernity, 66 associations were sizable (correlation coefficient $>0.20$ ). 
Of these 66 sizable associations, 63 were positive and 3 were negative. This can be considered overwhelming evidence in support of the proposition that the benefits of modernization generally outweigh the drawbacks. At a global level there were 29 sizable positive associations, compared to no sizable negative associations.

\section{Western nations}

Might it still be possible that modernization has gone too far? In order to answer this question, we conducted a separate analysis of 22 Western countries. It might be the case that the positive association between modernity and happiness that exists at a global level does not exist within the highly modern Western context. Of the 45 associations that were investigated, 37 were sizable. Of these 37 sizable associations, 34 were positive and 3 were negative. The benefits of farreaching modernization within the Western context therefore almost always outweigh the drawbacks. Moreover, all three exceptions (sizable negative associations) were associated with the same indicator: the size of the service sector. While the size of the service sector is still positively associated with happiness at a global level, in Western countries the associations are predominantly negative.

A second way in which we investigated whether modernization can go too far is by comparing the linear fit of the data with the quadratic fit. In doing so, we focused primarily on identifying any downward curving parabolas. This pattern was found in three instances. At a global level, we discovered a downward curving parabolic pattern in the association between industrialization and happiness, and in the association between affluence and happiness. We also found a downward curving parabolic pattern in the relationship between affluence and happiness in Western countries. However, it is impossible to tell from the corresponding scatter plots ${ }^{14}$ whether there is a clear turning point.

\subsection{Explanation of results}

Why does modernity generally promote happiness?

Based on the need theory of happiness as defended by Veenhoven (2009b) it is unsurprising that modern society makes people happier, since in this type of society favourable conditions exist that enable people to provide for their elementary needs (food, safety, etc.). Modern society not only meets these 'deficiency needs' but also provides favourable conditions for gratifying 'growth needs', such as intellectual development.

However, when we control for affluence we still see that modern society is positively associated with happiness. This could be due to the greater freedom of choice in modern societies. If we assume that in addition to having a shared biological basis people also have individual characters with their own capacities and preferences, it is logical that societies which only offer a single way of living will not score as well as multiform societies that are also stable enough to absorb this multiformity. This explanation is discussed in more detail in Veenhoven (1999, 2010e) 
Contradiction with ideas of modern uprootedness

In the introduction to this article we referred to a number of influential sociologists who brought the negative aspects of modern society to light, such as Putman in his book 'Bowling Alone'. Are these sociologists wrong? As mentioned previously, there are benefits and drawbacks to modernization. The relatively strong family ties found in Southern European countries offer unmistakable benefits, but the fact that the happiness scores obtained for these countries were lower than those obtained for Northern European countries indicates that there are also disadvantages at play, which outweigh the benefits on balance. One of the less obvious disadvantages may be reduced freedom to act, and in this context it is important to bear in mind that while people may be social animals, they are not herd animals. The human species underwent its greatest evolutionary changes when people were hunter-gatherers, and the social order associated with this era allowed individuals a large degree of freedom. This is why people flourish more today, with the 'weak' social ties of modern society, than with the 'strong' ties that are characteristic of traditional agrarian societies (Maryanski \& Turner 1992).

Contradiction with idea of socially-determined nature of happiness

The results of this study are also in conflict with cultural relativist notions of incomparability of different cultures, a view which goes hand-in-hand with a cognitive theory of happiness in which life is assessed using local standards of the good life. In this view, happiness is not determined by objective living conditions, but by the extent to which life meets current standards. As people living in different forms of society have different standards, 'better' living conditions do not lead to greater happiness by definition. However, the facts presented here indicate that people do feel better in counties that create better living conditions.

This study also highlights the fact that people have more in common than social constructivists believe is possible. What we see here is a universal pattern of conditions for happiness. This point is developed in further detail in Veenhoven (2010c).

Is happiness a good criterion?

Not everyone values happiness equally much, and in traditional societies spiritual welfare is often thought to be more important than earthly happiness. Does this fact disqualify this study? The answer is 'no'. First, there is little difference in the value attached to happiness in different countries, since happiness ranks high in the hierarchy of values everywhere (Veenhoven 2010c). Second, even if happiness might not be valued in a society, we can still judge a society on its happiness returns. Likewise, we condemn torture in countries where people attach little value to human rights. Third, subjective happiness is not only valuable in itself, but it is also a signal of human thriving in an objective sense. Happiness is driven by affective experience in the first place and the main biological function of positive and negative affect is to inform organisms on 
whether they are doing good or bad (Veenhoven 2010d). In this context happiness denotes a good fit of society with human nature.

Why a negative correlation with size of the service sector?

Within the subset of 22 western nations we found a slight negative correlation with size of the service sector that became more pronounced after control for affluence. This pattern appeared in the relationship with all three measures of happiness. The reason is in the unexpected low scores on size of the service sector for Ireland and Norway, which tilt the relationship to the negative. This could be a measurement issue.

How should the non-linear associations with happiness be interpreted? If we limit ourselves to the results for overall happiness, we find five non-linear associations $^{15}$.

First, there is a slight downward curving parabolic pattern in the relationship between industrialization and happiness at a global level. The reason is in this case that oil producing countries such as Algeria, Angola, Nigeria and Saudi Arabia are rated high on industrialization and thus distort an otherwise linear pattern.

Second, in Figure 2 we saw a downward curving parabolic pattern (with features of a logarithmic pattern) in the relationship between affluence and happiness at a global level. Similar patterns of diminishing returns in the relationship between affluence and happiness have been found previously, and were first described by Veenhoven (1989). This is compatible with the abovementioned need theory of happiness, since it is vital to avoid poverty in order to satisfy biological human needs, but it is not necessary to be rich. This is not in contradiction with the study carried out by Deaton (2008), as referred to in the introduction. Deaton did report a linear association with 'contentment', that is with the cognitive component of happiness. We also observed a linear relationship between affluence and contentment in this study. Contentment is the perceived realization of 'wants' and wants tend to be endless, while 'needs' are not.

Third, we discovered upward curving parabolic associations between education and happiness, and between democracy and happiness, at a global level. There is a good explanation for the slopes seen in these associations. Education and democracy provide greater benefits if the state is more robust, the government is more technically skilled, and the economy has been developed. It is harder to explain the dip in this parabola.

Finally, we discovered a downward curving parabolic pattern in the relationship between affluence and happiness in 22 Western countries. This might indicate that an optimum level of affluence has been crossed. Yet an inspection of the scatter plots shows that the parabolic pattern almost entirely due Iceland (very happy at that time) and Luxembourg, were the extremely high income per head is a fiscal artefact. 


\section{CONCLUSION}

The question raised in this article was whether modernization has gone too far, resulting in a lower quality of life in modern societies. The answer to this question is in the negative. People not only live longer in modern societies, they are also happier. For the time being, any drawbacks to modernization are more than made up for by its benefits. 


\section{LITERATURE}

Baltatescu, S. (2006)

Transition is over, wait to see the benefits: A comparative evaluation of the effects of post-communist transition on life satisfaction,

presented at The End of Transition?' conference in Budapest, Hungary

Bentham, J. (1789)

Introduction to the principles of Morals and Legislation,

London, UK

Berg, M. \& Veenhoven, R. (2010)

Income inequality and happiness in 119 nations: in search for an optimum that does not appear to exist,

In Greve, B. (ed) 'Social Policy and Happiness in Europe', Edgar Elgar

Bjornskov, C., Dreher, A. \& Fischer, J.A. (2008)

Cross-Country Determinants of Life Satisfaction: Exploring Different Determinants across Groups, in Society,

Social Choice and Welfare, 30, 119-173

Cantril (1965)

The pattern of human concerns,

Rutgers University Press, NJ, USA

CIA (Central Intelligence Agency) (2009)

The World Factbook,

https://www.cia.gov/library/publications/the-world-factbook/fields/2012.html

Deaton, A. (2008)

Income, Health and Wellbeing around the World:Evidence from the Gallup World

Poll,

Journal of Economic Perspectives, 22, 53-72

Dreher (2010)

KOF index of Globalization, http://globalization.kof.ethz.ch

Easterlin, R. (1973)

Does Money Buy Happiness?

The Public Interest, 30, 3-10

Elias, N. (2000)

The civilizing process,

Blackwell (revised edition)

Estes, R. (1984)

The social progress of nations,

Preager, New York, USA

Etzioni, A. (1993)

The spirit of community: The reinvention of American society,

Simon \& Schuster, New York, USA 
Fischer, C. (1984)

The Urban Experience,

New York, USA

Hagerty, M.R. (2003)

Was life better in the good old days? Intertemporal judgement of life-satisfaction, Journal of Happiness Studies, 4, 115-139

Hays, D.G. (1994)

On the painfulness of progress,

Cross Cultural Research, 28, 322-326

Heritage Foundation (2007)

Economic freedom in nations,

http://www.heritage.org

Illich, I. (1971)

De schooling society,

Mass Market paperbacks

Inkeles, A. (1970)

The Fate of Personal Adjustment in the Process of Modernization, International Journal of Comparative Sociology, 11, 5-114

Inglehart, R. \& Welzel, C. (2005)

Modernization, Cultural Change and Democracy,

Cambridge University Press, UK

Lane, R. (2000)

The loss of happiness in market democracies,

Yale University Press, New Haven, NJ, USA

Marx, K (1871)

Das Kapital. Collected works,

Akademie Verlag, Berlin, Germany

Nolan, P. \& Lenski, G. (2008)

Human societies: An introduction to macro sociology,

Paradigm Publishers, CA, USA

Poggi, C (1978)

The development of the modern state: a sociological introduction, Stanford University Press, USA

Putnam, R.D. (2000)

Bowling alone: The collapse and survival of American community, Simon \& Schuster, New York, USA

Ritzer, G. (1993)

The McDonaldization of society,

Pine Forge Press, Thousand Oaks, CA, USA 
Sociaal en Cultureel Rapport (2004)

In het zicht van de toekomst,

Netherlands Institute for Social Research, Netherlands

Starr, A. (2005)

Global revolt: a guide to movements against globalization,

Zed Books, USA

UNDP (United Nations Development Program) (1990)

Human Development Report: Concept and measurement of human

development,

Oxford University Press, New York, USA

Veenhoven, R. (1984)

Conditions of happiness,

D. Reidel, Dordrecht/Boston, $461 \mathrm{pp}$.

Veenhoven, R. (1989)

National Wealth and Individual Happiness,

in Grunert, K.G. \& Olander, F. (eds) Understanding Economic Behavior,

Kluwer Academic, Dordrecht, Netherlands, 9-32

Veenhoven,R. (1998)

Vergelijken van geluk in landen,

Sociale Wetenschappen, 42, 58-84

Veenhoven, R. (1999)

Quality-of-life in individualistic society: A comparison in 43 nations in the early 1990's,

Social indicators Research, 48:157-186

Veenhoven, R. (2002)

Het grootste geluk voor het grootste aantal: Geluk als richtsnoer voor beleid,

Sociale Wetenschappen, 4, 1-43

Veenhoven, R. (2005)

Apparent quality of life: How long and happy people live,

Social Indicators Research, 71, 61-86

Veenhoven, R. (2007)

Als geld niet gelukkig maakt, waarom werken we dan zo hard?

in Van der Steen, J. \& Van Heeswijk, J. (eds) Geld speelt geen rol. Een

verschuiving in waarden van welvaart naar welzijn?

Veenhoven, R. (2009a)

Well-being in nations and well-being of nations: Is there a conflict between

individual and society?

Social Indicators Research, 91, 5-21 
Veenhoven, R. (2009b)

How do we assess how happy we are? in Dutt, A. K. \& Radcliff, B. (eds.)

Happiness, Economics and Politics: Towards a multi-disciplinary approach,

Edgar Elgar Publishers, Cheltenham, UK, chapter 3, 45-69

Veenhoven, R. (2010a)

States of Nations: Data file for the cross national analysis of happiness,

World Database of Happiness,

http://worlddatabaseofhappiness.eur.nl/statnat/statnat_fp.htm

Veenhoven, R. (2010b)

Trend average happiness in nations 1946-2008: How much people like the life they live,

World Database of Happiness, Erasmus University Rotterdam, http://worlddatabaseofhappiness.eur.nl/hap_nat/findingreports/TrendRepor

t_AverageHappiness.pdf.

Veenhoven (2010c)

How universal is happiness? in Diener, E., Helliwell, J.F. \& Kahneman, D. (eds) International Differences in Well-Being,

Oxford University Press, NY, USA, chapter 11

Veenhoven, R. \& Hagerty, M. (2005)

Rising happiness in nations, 1946- 2004: A reply to Easterlin,

Social Indicators Research, 79, 421-436

Veenhoven, R. (2010d).

Greater happiness for a greater number: Is that possible and desirable? Journal of Happiness Studies (in press)

Veenhoven, R. (2010e)

Life is getting better: Societal evolution and fit with human nature,

Social Indicators Research (2010) 97:105-122

Wirth, L. (1938)

Urbanism as a way of life,

American Journal of Sociology 


\section{NOTES}

${ }^{1}$ Variable IndustrialShareGDP_2006 in States of Nations data file (Veenhoven 2010)

${ }^{2}$ Variable ServiceShareGDP_2007 in States of Nations data file (Veenhoven 2010)

${ }^{3}$ Variable FreeEconIndex2_2007 in States of Nations data file (Veenhoven 2010)

${ }^{4}$ Variable GlobalizationIndex2 2010 in States of Nations data file (Veenhoven 2010)

${ }^{5}$ Variable RGDP 2005 in States of Nations data file (Veenhoven 2010)

${ }^{6}$ Variable EducationIndex2_2000.04. in States of Nations data file (Veenhoven 2010)

${ }^{7}$ Variable DemocracyIndex5_06 in States of Nations data file (Veenhoven 2010)

${ }^{8}$ Variable UrbanPopulation_2005 in States of Nations data file (Veenhoven 2010)

${ }^{9}$ Variable HappinessLSBW10.11_2009.09 in States of Nations data file (Veenhoven 2010). This variable consists of answers to more or less identical questions posed in various surveys conducted in different years during this period. In the many cases where a number of observations were available, an average was calculated.

${ }^{10}$ Variable HappinessYesterdaysABS_2006.08 in States of Nations data file (Veenhoven 2010). Incidentally, the emotion that an individual had 'yesterday' is not a good indicator of his or her happiness since happiness refers to a more structural experience of life and the individual might have just happened to have had either a good day or a bad day. However, the average emotion within a population is a useful indicator of national happiness because fluctuations that are due to arbitrary factors cancel each other out. Moreover, one advantage of asking respondents about how they felt the previous day is that it reduces the likelihood that biased responses will be given.

${ }^{11}$ Variable HappinessBW11Gallup_2006.09 in States of Nations data file (Veenhoven 2010)

${ }^{12}$ It is striking that the happiness score of Costa Rica is so high, and is even higher than Denmark's. Some caution should be exercised as Costa Rica's score was based on one survey that included just 1000 respondents. Against this, it should be noted that Costa Rica also scored highly in the Latino Barametro. ${ }^{13}$ Plots not presented in this paper are available at http://www2.eur.nl/fsw/research/veenhoven/Pub2010s/2011a-supplement.pdf

${ }^{14}$ The scatter plot is available on the web, see note 13.

${ }^{15}$ Only the first of these is presented in this article owing to a lack of space. The other three are available on the web (see note 13) 

